Claudia Cappelli Aló

\title{
Uma Abordagem para Transparência em Processos Organizacionais Utilizando Aspectos
}

Tese apresentada ao Programa de Pós-Graduação em Informática do Departamento de Informática da PUC-Rio como parte dos requisitos parciais para obtenção do título de Doutor em Ciências - Informática.

Orientador: Julio Cesar Sampaio do Prado Leite

Rio de Janeiro

Agosto de 2009 


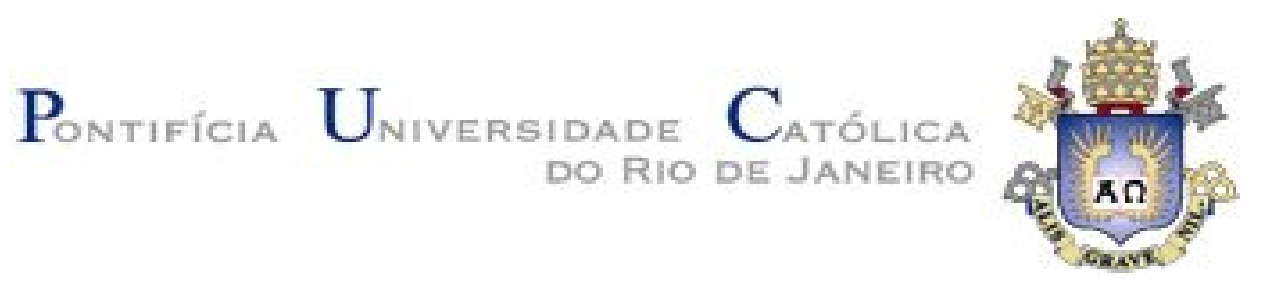

Claudia Cappelli Aló

\title{
Uma Abordagem para Transparência em Processos Organizacionais Utilizando Aspectos
}

Tese apresentada como requisito parcial para obtenção do grau de Doutor pelo Programa de Pós-graduação em Informática do Departamento de Informática do Centro Técnico Científico da PUC-Rio. Aprovada pela Comissão Examinadora abaixo assinada.

\author{
Julio Cesar Sampaio do Prado Leite \\ Orientador \\ Departamento de Informática - PUC-Rio
}

Prof. Rubens Nascimento Melo

Departamento de Informática - PUC-Rio

Prof. Luis Carlos de Sá Carvalho Departamento de Administração - PUC-Rio

Profa. Vera Maria Benjamim Werneck

Departamento de Informática - UERJ

Profa. Thais Vasconcelos Batista Departamento de Informática - UFRN

Prof. José Eugenio Leal Coordenador Setorial do Centro

Técnico Científico

Rio de Janeiro, 10 de agosto de 2009. 
Todos os direitos reservados. É proibida a reprodução total ou parcial do trabalho sem autorização do autor, do orientador e da universidade.

\section{Claudia Cappelli Aló}

Graduou-se em Informática na Universidade do Estado do Rio de Janeiro (UERJ) em 1985. Obteve o título de Mestre em Informática pela Universidade Federal do Rio de Janeiro (NCE/UFRJ) em 2000. É pesquisadora associada no Núcleo de Pesquisa e Prática de Tecnologia da Universidade Federal do Estado do Rio de Janeiro (UNIRIO). Integrou o quadro de pesquisadores do Laboratório de Engenharia de Software (LES) da PUC-Rio, atuando na área de Engenharia de Requisitos.

Ficha Catalográfica

Aló, Claudia Cappelli

Uma abordagem para transparência em processos organizacionais utilizando aspectos / Claudia Cappelli Aló; orientador: Julio Cesar Sampaio do Prado Leite. - 2009.

328 f. : il.; $30 \mathrm{~cm}$

Tese (Doutorado em Informática) - Pontifícia Universidade Católica do Rio de Janeiro, Rio de Janeiro, 2009.

Inclui bibliografia

1. Informática - Teses. 2. Transparência. 3. Transparência Organizacional. 4. Modelagem de Processos Orientada a Aspectos. 5. Aspectos de Transparência. 6. Transparência em Processos Organizacionais. Leite, Julio Cesar Sampaio do Prado. II. Pontifícia Universidade Católica do Rio de Janeiro. Departamento de Informática. III. Título.

CDD: 004 


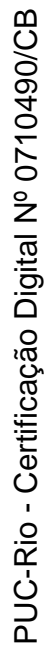

Ao meu filho Ugo, minha mãe Maria e meu pai Antonio (em memória), por todo amor, ajuda e incentivo. 


\section{Agradecimentos}

Florianópolis, 30/12/2004. Viagem de férias. Passagem de ano. Ligo para casa para saber como estão as coisas e para falar com minha mãe Maria, companheira e amiga de todas as horas. Recebo a notícia de que chegou uma correspondência da PUC-Rio. Peço que ela abra e que me diga o que está escrito. Fico nervosa. Afinal, estava esperando a resposta do processo de seleção para o Doutorado. Ela lê e me diz que fui aprovada. Estava no quarto do hotel. Olhei pela janela e vi um pôr do sol lindo. Agradeci a Deus que sempre guiou meus caminhos colocando neles oportunidades como esta. Chorei. Queria abraçar todo mundo. Compartilhar com todos a minha felicidade. Ao meu lado no quarto estava Agostinho, meu companheiro que certamente viria a me ajudar muito nesta nova jornada com sua compreensão e apoio. Abracei-o ainda chorando um pouco e contei o que havia acontecido. Ele ficou feliz.

Logo depois, olhando pela sacada, avistei meu filho $\boldsymbol{U} \boldsymbol{g o}$ voltando da praia. Saí do quarto, desci as escadas. Queria abraçá-lo e contar a novidade. Ele, quando soube, me deu todo apoio e disse que poderia contar com ele em todas as horas. Eu certamente iria precisar. E durante todo o meu percurso foi o que aconteceu. Mas ainda precisava falar com mais uma pessoa. Renata, minha querida amiga e companheira que me incentivou muito a enfrentar este novo desafio na minha vida. Liguei. Ela atendeu. Contei a novidade e senti que ela ficou muito feliz. Certamente dali para frente nós estaríamos ainda mais próximas. Veio o dia seguinte. Ano Novo. E naquele ano realmente vida nova. Afinal só se inicia um Doutorado uma vez. Voltei ao Rio e não via a hora de fazer a matrícula e começar o curso. 
Finalmente o dia chegou. Novo curso, novos professores, novos amigos. Viterbo, Marcia, Luciana e Tanara, pessoas maravilhosas com quem pude conviver ao longo do curso e com quem, apesar de áreas e orientadores diferentes, criei uma grande amizade. Mas nem tudo são flores. Matérias difíceis, porém obrigatórias, tinham que ser cumpridas. $\mathrm{O}$ primeiro ano, um desafio conseguir permanecer no curso. Nestas horas a ajuda das amigas Flávia, Fernanda, Renata, Andrea, Vanessa, Hadeliane foi vital. Minhas queridas amigas que durante toda a jornada do curso me ajudaram muito, pois estávamos todas envolvidas em projetos de trabalho e eu precisaria me ausentar muitas vezes. A elas o meu muito obrigada. Sem elas certamente não teria sido possível. Mas isso era só o começo. Afinal ainda tinha alguns anos pela frente. Nos dois primeiros anos ainda trabalhei fortemente nos projetos em que eu estava envolvida. Estes me eram muito enriquecedores, pois me davam experiência e material que certamente seriam úteis no trabalho do Doutorado. Nestes também tive a oportunidade de contato com diversas pessoas em universidades distintas, uma delas a Profa. Thais Batista, que conheci em um destes projetos e hoje também está presente em minha banca. A ela o meu muito obrigada pelo incentivo e apoio.

A partir do segundo ano passei a ter contato mais direto com meu orientador, pessoa que aprendi a admirar por seu conhecimento e novas ideias e que sempre apoiou as minhas escolhas, Prof. Julio Leite. Foi ele que me mostrou o caminho a ser seguido e, juntos, escolhemos o tema do meu trabalho. Durante o segundo ano continuei cursando algumas matérias, porém já me aprofundava no tema escolhido. Tive a oportunidade de estudar em outros Departamentos da Universidade e conheci outros professores, entre eles o Prof. Sá Carvalho, com quem discuti muito sobre organizações e processos e que hoje está presente na minha banca. Agradeço a ele pelos ensinamentos. Neste ano também foi reativado o Grupo de Engenharia de Requisitos. Nele conheci pessoas muito interessantes como Pádua, Eduardo, Filipe, Herbet e Elizabeth, que me ajudaram e com quem discuti muitas vezes sobre o tema escolhido. Agradeço a todos pela colaboração. Além deles a Profa. Vera Werneck, que faz parte do grupo e que hoje está presente na minha banca, também merece meu agradecimento .

O trabalho começou a tomar corpo. Tivemos as primeiras publicações. Estava tudo indo bem e eu estava radiante. Acreditava no tema escolhido, na importância de meu estudo para a comunidade acadêmica e na sua aplicação no contexto das 
organizações. Precisava me dedicar mais ao Doutorado, mas neste período, meu pai, Antonio, adoeceu. Foi difícil, pois sabia que era uma doença terminal. Queria ficar com ele o máximo de tempo possível, mas isso me faria muitas vezes relegar o estudo ao segundo plano. O tempo passou muito rápido. O final do terceiro ano chegou e meu pai se foi. Sinto muito sua falta, mas tenho certeza de que está feliz por saber que consegui chegar ao fim deste trabalho. Ele sempre me apoiou muito.

Finalmente o quarto ano. Precisava correr, pois os prazos finais começavam a dar sinais. Pesquisa para terminar, estudos de caso para fazer, artigos para publicar, projetos para participar.Faltava muito e o tempo era pouco. Esforcei-me. Aumentei muito minha dedicação. Trabalhei. Atrasei um pouquinho, mas finalmente, cheguei ao final do trabalho. Agora faltavam os preparativos para a defesa. Fechar o trabalho, revisar, escolher a banca. Nesta fase conheci o Prof. Rubens que hoje está fazendo parte da minha banca. A ele meus agradecimentos. Tudo pronto. Gostei muito do que fiz. Tenho planos para o futuro. Espero ter novas oportunidades. Mas por hora só tenho mesmo a agradecer a todos por tudo e esperar que tudo dê certo.

Agradecimento especial ao $\mathrm{CNPq}$ pela bolsa concedida para apoio ao desenvolvimento deste trabalho. 


\section{Resumo}

Aló, Claudia Cappelli; Leite, Julio Cesar Sampaio do Prado. Uma Abordagem para Transparência em Processos Organizacionais Utilizando Aspectos. Rio de Janeiro, 2009. 328 p. Tese de Doutorado Departamento de Informática, Pontifícia Universidade Católica do Rio de Janeiro.

Transparência tem sido por tempos um anseio das sociedades democráticas. $\mathrm{O}$ direito de ser informado e de ter acesso à informação tem sido um problema importante nas sociedades modernas. A demanda por verdades baseadas na transparência tem aumentado no contexto das transformações globais. A importância da abertura do fluxo de informações está criando uma sociedade aberta na qual o objetivo é o estabelecimento de uma sociedade democrática com cidadãos engajados capazes de entender e acessar as informações disponíveis (Holzner, 2006). Entretanto, não é suficiente para uma organização desejar ser transparente. As organizações precisam saber o que é transparência e como elas podem inserir este conceito no seu negócio. Esta tese define transparência e a forma de aplicá-la aos processos de negócio utilizando-os como meio de explicitar a transparência dentro de organizações. Para isso, propõe uma abordagem orientada a aspectos que permita introduzir características de transparência nos processos organizacionais através da construção de políticas e padrões, e da inserção de elementos nos modelos de processos organizacionais com uso de um catálogo de transparência. Para validar a proposta da definição de transparência, foi conduzida uma análise de processos organizacionais através de dois levantamentos utilizando questionários. Para a validação da abordagem proposta, foi realizado um estudo de caso a partir de processos de negócio de uma organização real. Este estudo de caso permitiu a obtenção de alguns resultados preliminares sobre a aplicabilidade e viabilidade do uso desta abordagem.

\section{Palavras-chave}

Transparência, Transparência Organizacional, Modelagem de Processos Orientada a Aspectos, Aspectos de Transparência, Transparência em Processos Organizacionais. 


\section{Abstract}

Aló, Claudia Cappelli; Leite, Julio Cesar Sampaio do Prado (Advisor). An approach for Business Processes Transparency Using Aspects. Rio de Janeiro, 2009. 328 p. Doctoral Thesis - Departamento de Informática, Pontifícia Universidade Católica do Rio de Janeiro.

Transparency has been a desire of democratic societies for a long time. The right to be informed and have access to information has been a major problem in modern societies. The demand for truth based on transparency has increased in the context of global change. The importance of openness in the flow of information is creating an open society in which the very idea is to establish a democratic society with engaged citizens able to understand and use the information that is accessible to them (Holzner, 2006). However, it is not sufficient for an organization to wish to be transparent. Organizations need to know what transparency is and how they can apply this concept to their business. This thesis defines transparency and a way of using it in business processes, using these processes as a means of making explicit the transparency within organizations. An aspect oriented approach is proposed in order to allow the introduction of transparency characteristics into business processes. Policies and standards are proposed as well as a technique for inserting new elements into the business processes using a transparency catalog. In order to validate the proposed definition of transparency, an analysis of organizational processes, using two surveys, was performed. A case study, using the business processes from of a real organization, was performed to validate the proposed approach. This case study produced some preliminary results on the applicability and feasibility of using this approach.

\section{Keywords}

Transparency, Organizational Transparency, Aspect Oriented Business Process Model, Transparency Aspects, Business Process Transparency. 


\section{Sumário}

1. Introdução 16

$\begin{array}{ll}1.1 \text { Motivação } & 16\end{array}$

$\begin{array}{ll}1.2 \text { Caracterização do Problema } & 19\end{array}$

1.3 Enfoque da Solução 20

$\begin{array}{ll}1.4 \text { Organização da Tese } & 21\end{array}$

2. Transparência 23

2.1 Características Gerais de Transparência 23

2.2 Organização das características $\quad 24$

$\begin{array}{ll}2.3 \text { Graus de Transparência } & 30\end{array}$

2.4 O levantamento realizado 33

$\begin{array}{ll}2.5 \text { A versão final do SIG } & 34\end{array}$

3. Transparência Organizacional 37

3.1 Trabalhos Relacionados - Transparência no contexto das organizações 37

3.2 Definição de Transparência Organizacional 45

3.3 O Catálogo de Transparência 46

$\begin{array}{ll}3.4 \text { Classificando as operacionalizações } & 67\end{array}$

3.5 Aplicação das operacionalizações a processos na web 72

3.6 Análise das contribuições - Uso do PCT 74

4. Inserção de práticas de transparência em processos organizacionais 86

4.1 Transparência - Uma Característica Transversal 86

4.2 O Paradigma de Aspectos $\quad 89$

4.3 Trabalhos Relacionados $\quad 90$

4.4 Processos Organizacionais Orientados a Aspectos 95

4.5 Aplicando o modelo apresentado para a inserção de características de transparência em modelos de processos organizacionais 112

5. Estudo de Caso 124

$\begin{array}{ll}5.1 \text { Objetivos } & 124\end{array}$

$\begin{array}{ll}5.2 \text { Etapas do Estudo de Caso } & 124\end{array}$

$\begin{array}{ll}5.3 \text { Formulação do Problema } & 125\end{array}$

5.4 Definição da Unidade-Caso 125

$\begin{array}{ll}5.5 \text { Determinação do número de casos } & 126\end{array}$

$\begin{array}{ll}5.6 \text { Elaboração do Protocolo } & 126\end{array}$ 
5.7 Operacionalização das características de transparência nos modelos de processo (unidades-caso)

5.8 Respostas às questões elaboradas

6. Conclusão

6.1 Contextualização

6.2 Resumo

6.3 Trabalhos relacionados em transparência

6.4 Estudos relacionados para a sistematização da definição de transparência

6.5 Trabalhos relacionados em aspectos

6.6 A avaliação da definição de transparência através de levantamentos

6.7 O Estudo de Caso - aplicação da abordagem de modelagem de processos orientada a aspectos

6.8 Contribuições

6.9 Limitações

6.10 Trabalhos Futuros

7. Referências

Apêndice A

Levantamento Baseado em Revisão Sistemática

Apêndice B

Revisão do SIG de transparência junto ao Grupo de Engenharia de

Requisitos da PUC

Apêndice C

Levantamento para validação do SIG e dos Graus de Transparência

Apêndice D

Questionário para verificação da Transparência de Processos Organizacionais através de sites da Web

Apêndice E

Questionário para verificação da Transparência em Processos Organizacionais 258

Apêndice F

Símbolos do Léxico relacionados à transparência organizacional

Anexo I

Modelos de Processos utilizados no Estudo de Caso 


\section{Lista de Figuras}

Figura 2.1 - Identificação de interdependências implícitas de softgoals (Chung, 2000)

Figura 2.2 - O SIG de transparência - Versão 1 (Cappelli, 2007) 28

Figura 2.3 - O SIG de transparência - Versão 2

Figura 2.4 - Degraus da Transparência (Cappelli, 2008; Leite, 2008) 31

Figura 2.5 - O SIG de transparência - Versão 3 (Cappelli, 2008) 34

Figura 2.6 - - O SIG de Transparência - Versão Final 36

Figura 3.1 - Notícias de transparência coletadas na web entre $12 / 05$ e $23 / 05 / 2009$

Figura 3.2 - - Transparência Organizacional 49

Figura 3.3 - - Acessibilidade $\quad 50$

Figura 3.4 - Acurácia $\quad 50$

Figura 3.5 - Adaptabilidade $\quad 51$

Figura 3.6 - Amigabilidade $\quad 51$

Figura 3.7 - Atualidade $\quad 52$

Figura 3.8 - Auditabilidade $\quad 52$

Figura 3.9 - Clareza $\quad 53$

Figura 3.10 - Comparabilidade $\quad 53$

Figura 3.11 - Completeza $\quad 54$

Figura 3.12 - Composição $\quad 54$

Figura 3.13 - Concisão $\quad 55$

Figura 3.14 - Consistência $\quad 55$

Figura 3.15 - Controle $\quad 56$

Figura 3.16 - Corretude $\quad 56$

Figura 3.17 - Dependência $\quad 57$

Figura 3.18 - Desempenho $\quad 57$

Figura 3.19 - Detalhamento $\quad 58$

Figura 3.20 - Disponibilidade $\quad 58$

Figura 3.21 - Divisibilidade $\quad 59$

Figura 3.22 - Entendimento $\quad 59$

Figura 3.23 - Explicação $\quad 60$

Figura 3.24 - Informativo $\quad 61$

Figura 3.25 - Integridade $\quad 61$

Figura 3.26 - Intuitividade $\quad 62$

Figura 3.27 - Operabilidade $\quad 62$

Figura 3.28 - Portabilidade $\quad 63$

Figura 3.29 - Publicidade $\quad 63$

Figura 3.30 - Rastreabilidade $\quad 64$

Figura 3.31 - Simplicidade $\quad 65$

Figura 3.32 - Uniformidade $\quad 65$

Figura 3.33 - Usabilidade $\quad 66$

Figura 3.34 - Validade $\quad 66$

Figura 3.35 - Verificabilidade $\quad 67$

Figura 3.36 - SIG de Transparência com contribuições em rede entre

Figura 3.37 - Fórmulas para comparar os construtos $\quad 77$

Figura 3.38 - SIG de Transparência (Final) com contribuições entre critérios $\quad 84$

Figura 3.39 - Léxico do relacionamento entre uniformidade e clareza $\quad 84$ 
Figura 3.40 - Léxico do relacionamento entre simplicidade, completeza e concisão

Figura 3.41 - Léxico do relacionamento entre concisão e completeza 85

Figura 3.42 - Léxico do relacionamento entre corretude e integridade 85

Figura 3.43 - Léxico do relacionamento entre dependência e rastreabilidade $\quad 85$

Figura 4.1 - Abordagem tradicional de modelagem $\quad 88$

Figura 4.2 - Metamodelo de integração de características transversais

(Silva, 2006)

Figura 4.3 - Componentes usados para integrar relacionamentos transversais em modelos de processos (adaptado de Silva (Silva, 2006))

Figura 4.4 - Sintaxe de LMPOA (adaptado de Silva (Silva, 2006))

Figura 4.5 - Modelo conceitual da linguagem de modelagem de processos orientada a aspectos (adaptado de Silva (Silva, 2006))

Figura 4.6 - Sintaxe do Relacionamento Transversal

Figura 4.7 - Características transversais e seus relacionamentos com demais elementos

Figura 4.8 - Exemplo de Aspecto - Obter Formulário Solicitação Mudança

106

Figura 4.9 - Exemplo de Aspecto - Enviar Solicitação de Mudança 107

Figura 4.10 - Exemplo de Aspecto - Formulário Solicitação Mudanças 107

Figura 4.11 - Exemplo de Aspecto - Dados Requisição

108

Figura 4.12 - Composição das características transversais (Cappelli, 2009b) 109

Figura 4.13 - Composição das características transversais - Formato Texto

(Cappelli, 2009b)

Figura 4.14 - Visão de Documentos - As atividades que utilizam

o documento

Figura 4.15 - Visão de Dados - As atividades que utilizam um conjunto de informações

Figura 4.16 - Visão de Atividades - Repetição

Figura 4.17 - Visão de Atividades Principais

Figura 4.18 - Processo "Inserir Aspectos de Transparência em Processos"

Figura 4.19 - Componentes usados para integrar transparência em modelos de processos (adaptado de Silva (Silva, 2006))

Figura 4.20 - Processo Genérico de Contratação de Software (adaptado de

(Magdaleno, 2006))

Figura 4.21 - Aspectos Transversais do Processo "Gerir Contratação

de Software"

Figura 4.22 - Processo Genérico de Gerir Contratação de Software

com elementos de transparência

Figura 4.23 - Controlabilidade - Visualização dos pontos de controle no processo

Figura 4.24 - Integridade - Visualização dos pontos de uso das fontes de informação do processo

Figura 4.25 - Explicação - Visualização dos pontos de tomada de decisão no processo e suas justificativas

Figura 5.1 - Processo "Levantar Informações do Estudo de Caso" 130

Figura 5.2 - Processo Preparar Intervenção de Manutenção com aspectos 141

Figura 5.3 - Processo Preparar Intervenção de Investimento com aspectos 146

Figura 5.4 - Processo Acompanhar Intervenção com aspectos 


\section{Lista de Tabelas e Quadros}

Tabela 2.1 - Características Transparência X Lista Características NFR 27

Tabela 2.2 - Definições das características do NFR Framework - Versão 127

Tabela 2.3 - Definições das características do NFR Framework - Versão 229

Tabela 2.4 - Definições das características do NFR Framework - Versão Final 35

Tabela 3.1 - Implementação das Operacionalizações - parte 1

Tabela 3.2 - Implementação das Operacionalizações - parte $2 \quad 70$

Tabela 3.3 - Implementação das Operacionalizações - parte 3

Tabela 3.4 - Resultado da aplicação do questionário sobre sites

na web - parte $1 \quad 72$

Tabela 3.5 - Resultado da aplicação do questionário sobre sites

na web - parte 2

Tabela 3.6 - Um exemplo de repertory grid (Ford, 1991) 76

Tabela 3.7 - Respostas do melhor caso em cada uma das características $\quad 78$

Tabela 3.8 - Respostas do pior caso em cada uma das características $\quad 79$

Tabela 3.9 - Respostas do melhor caso em cada uma das características

- Binário $\quad 80$

Tabela 3.10 - Respostas do pior caso em cada uma das características - Binário 80

Tabela 3.11 - Relacionamentos entre construtos do melhor caso 81

Tabela 3.12 - Relacionamentos entre construtos do pior caso 82

Tabela 4.1 - Regras de Composição do Relacionamento Transversal 104

Tabela 4.2 - Parâmetros de Visualização 104

Tabela 4.3 - Relacionamento entre os elementos do modelo 105

Tabela 5.1 - Perfil dos entrevistados no estudo de caso 128

Tabela 5.2 - Avaliação Processo Preparação Intervenção de Manutenção - parte 1

Tabela 5.3 - Avaliação Processo Preparação Intervenção de Manutenção - parte 2

Tabela 5.4 - Avaliação Processo Preparação Intervenção de Manutenção

- parte 3

Tabela 5.5 - Avaliação Processo Preparação Intervenção de Investimento - parte 1

Tabela 5.6 - Avaliação Processo Preparação Intervenção de Investimento - parte 2

Tabela 5.7 - Avaliação Processo Preparação Intervenção de Investimento - parte 3

Tabela 5.8 - Avaliação Processo Acompanhar Intervenção - parte $1 \quad 136$

Tabela 5.9 - Avaliação Processo Acompanhar Intervenção - parte $2 \quad 137$

Tabela 5.10 - Avaliação Processo Acompanhar Intervenção - parte $3 \quad 137$

Tabela 5.11 - Mecanismos ausentes no Processo Preparar Intervenção de

Manutenção

Tabela 5.12 - Elementos ausentes no Processo Preparar Intervenção de

Manutenção

Tabela 5.13 - Mecanismos ausentes no Processo Preparar Intervenção de Investimento

Tabela 5.14 - Elementos ausentes no Processo Preparar Intervenção de 


\section{Lista de Abreviaturas e Siglas}

ADL - Arquitectural Description Language

AO - Aspect Oriented

AO-BPM - Aspect Oriented Business Process Model

BASEL - Basel Committee on Banking Supervision

BPM - Business Pross Management

BPMN - Business Process Modeling Language

CGU - Corregedoria Geral da União

CMMI - Capability Maturity Model Integration

DSOA - Desenvolvimento de Software Orientado a Aspectos

EITI - Extractive Industries Transparency Initiative

EPC - Event Process Chain

EROA - Engenharia de Requisitos Orientada a Aspectos

FoIA - Freedom of Information Act

IBGC - Instituto Brasileiro de Governança Corporativa

LMPOA - Linguagem de Modelagem de Processos Orientada a Aspectos

LMROA - Linguagem de Modelagem de Requisitos Orientada a Aspectos

NFR - No Functional Requirement

OCDE - Organização para a Cooperação e Desenvolvimento Econômico

PCT - Personal Construct Theory

POA - Programação Orientada a Aspectos

SOX - Sarbanes-Oxley

TB - Transparência Brasil

TCC - Transparência, Consciência e Cidadania

TI - Transparency International

Web - World Wide Web 